\title{
La política británica hacia España en el Trienio Constitucional
}

\author{
ana Clara Guerrero *
}

Gran Bretaña había tenido un papel fundamental en el diseño de la Europa que salió del Congreso de Viena. El gobierno "tory" presidido por el conde de Liverpool había encargado el diseño de su política exterior al Vizconde de Castlereagh, quien, siguiendo de cerca las máximas expresadas por Pitt en su Memorandum de 19 de enero de $1805^{1}$, centró su actuación en controlar a Francia y conseguir un sistema de equilibrio de poderes en Europa. La celebración periódica de congresos internacionales entre las grandes potencias continentales y la dueña de los mares era el instrumento diseñado para restaurar y mantener el equilibrio deseado. Por otra parte, Castlereagh no olvidaba que Gran Bretaña era una potencia mundial y las relaciones con el mundo colonial tuvieron un importante papel en su concepción política. Marcando distancias frente a anteriores secretarios de Estado, se preocupó por mejorar las relaciones entre los Estados Unidos y su antigua metrópoli, convencido de que habría que contar con ellos para mantener o ampliar los intereses comerciales británicos en el continente americano en su conjunto.

Pero, en muy pocos años, se podría observar la diferente idea que las potencias continentales y la Gran Bretaña de Liverpool y Castlereagh tenían acerca de qué podía constituir una amenaza para el equilibrio logrado. Los cambios en el sistema de gobierno de algunos estados europeos, aun cuando en ocasiones fuesen en dirección no del todo acorde con los ideales británicos, no quitaban el sueño al gobierno "tory" y aun

* UNED.

1 Temperley, H. W. V. y PEnson, L., Foundations of British Foreign Policy. Londres 1938, pág. 11. 
menos a la oposición. En cambio, cualquier amenaza a la libertad de comercio, cualquier alteración en la situación colonial, debía ser estrechamente vigilada, no sólo para evitar que un cambio pudiese perjudicar a los intereses británicos, sino incluso para posibilitar la obtención de algún beneficio.

\section{CASTLEREAGH, WELLESLEY Y LA REVOLUCIÓN DE 1820}

La denominada por los británicos "guerra peninsular» había estrechado los vínculos entre España y Gran Bretaña, pero casi de forma inmediata al fin de las hostilidades empezaron a hacerse patentes las divergencias existentes entre ambos paises. Las noticias que enviaba Henry Wellesley, embajador británico en la corte española, preocupaban hondamente a Castlereagh, quien dudaba que el rey Fernando y sus consejeros fuesen capaces de realizar las reformas que Gran Bretaña consideraba indispensables en el sistema constitucional español. A pesar de estar informado de las buenas palabras y promesas del rey, temía que se dejase llevar por sus preferencias y reimplantase el antiguo sistema monárquico ${ }^{2}$. A esta divergencia en cuanto a la forma de gobierno español se unían, junto a los habituales roces por asuntos comerciales, diferencias de opinión sobre la manera en que España estaba haciendo frente a los problemas con sus colonias en América y un gran malestar por la resistencia española a firmar un acuerdo sobre el cese de la trata de esclavos. El estallido de la revolución de 1820 no cambiaría en los sustancial las preocupaciones de Castlereagh respecto a España -un gobierno inadecuado y una mala actuación en sus colonias americanas-, pero sería un nuevo elemento de tensión en las no siempre fáciles relaciones con los aliados.

A comienzos del año 1820, Henry Wellesley estaba dedicado a lo que durante más de un siglo venía siendo la ocupación principal de los embajadores británicos en Madrid, intentar obtener de la Corte española la redacción de un nuevo tratado de comercio que mejorase las condiciones del tráfico británico hacia la península y la situación de los comerciantes de dicha nacionalidad residentes en España. Las nuevas intruc-

2 3rd Marquess of Londonderry (ed.), Memoirs and Correspondence of Viscount Castlereagh. London 1848-54, Vol. X, pág. 26. De Castlereagh a Sir Henry Wellesley. 10 de mayo de 1814. 
ciones de Rentas aprobadas en 1816 y algunas otras reales órdenes posteriores alteraban, a su juicio, las prácticas establecidas por tratados u observadas antes de 1796, proporcionándole argumento suficiente para plantear la necesidad de una revisión de los acuerdos comerciales ${ }^{3}$. Cuando le llegan los primeros rumores de la insurrección de Riego se apresura a transmitirlos al Foreign Office, pero sus informes no son ni mucho menos alarmistas. No cree en el triunfo de la rebelión, ni siquiera en que responda a unos ideales claramente constitucionalistas, pues aunque han proclamado la Constitución de 1812, su movimiento "ha sido provocado fundamentalmente por no querer embarcarse para la expedición" ${ }^{4}$. Su opinión es corroborada por los informes de los cónsules en Andalucia; ninguno de ellos parece muy preocupado a causa de esos "rebeldes mal organizados" ${ }^{5}$. Uno de los aspectos de la insurrección que más llamaba su atención, dos semanas después del inicio de la insurrección, era «la completa apatía del pueblo, que no ha tomado partido ni de un lado ni del otro, sino que parece considerar que la lucha es entre el rey y el ejército" ${ }^{6}$. Solamente en ciudades como Madrid y Cádiz iba cobrando fuerza un nuevo estado de opinión favorable a los insurgentes.

Sin embargo, a finales de febrero, la correspondencia de Wellesley deja traslucir una mayor preocupación. Le han llegado noticias de que la insurrección avanza por varias provincias $y$, pese a los consejos que surgen de algunos sectores recomendando al monarca que convoque Cortes siguiendo las leyes antiguas y anuncie su propósito de dar una forma constitucional a su gobierno, el embajador británico desconfía de la capacidad del rey y sus ministros para promulgar algún decreto que pueda satisfacer al país. Por otra parte, desde su punto de vista, ya es difícil que los sublevados acepten nada que no sea la Constitución de $1812^{7}$. Ante la situación decide suspender su petición para ser relevado de su puesto, pues confía en que su experiencia al frente de las relaciones diplomáticas británicas con España pueda ser de utilidad a su gobierno. Desde estos momentos iniciales Henry Wellesley deja traslucir lo que muy pronto se convertirá en postura oficial de su Gobierno: su desagrado por la constitución de 1812 y su deseo y esperanza de que se

${ }^{3}$ Public Record Office (PRO). Foreign Office (FO) 72/234. Madrid 6 de enero de 1820. De Henry Wellesley a Castlereagh.

4 PRO: FO 185/80. Madrid 10 de enero de 1820 . De Henry Wellesley a Castlereagh.

${ }^{5}$ PRO: FO 72/234. Sevilla, 8 de enero de 1820.

6 PRO: FO 185/80. Madrid, 17 de enero de 1820. De Henry Wellesley a Castlereagh.

PRO: FO 72/234. Madrid, 7 de marzo de 1820. De Henry Wellesley a Castlereagh.

PRO: FO 185/80, 28 de febrero de 1820. De Henry Wellesley a Castlereagh. 
introduzcan en ella algunos cambios sustanciales, especialmente en lo referente a la existencia de dos Cámaras, ya que "ha quedado demostrado que dicha constitución es poco adecuada para España" ${ }^{8}$.

La reacción en el Foreign Office ante las noticias de la insurrección no se hace esperar. Castlereagh ya había expresado anteriormente su escasa confianza en la capacidad del rey y su camarilla para hacerse respetar por sus súbditos, así como su digusto por el sistema de gobierno impuesto tras el regreso de Fernando y su temor a una posible reacción en contra. El estallido de una crisis en España no le pillaba por sorpresa, pero había que actuar para evitar que la inevitable reacción de las potencias continentales debilitase en exceso el supuesto frente común europeo que tantos esfuerzos le había costado crear. Habia que perfilar y fundamentar una politica británica respecto al caso español, para poder responder a las presiones rusas, que desde el 3 de marzo insistian en la necesidad de formular una estrategia común por parte de los aliados ${ }^{9}$. Si existía un experto en cuestiones españolas en la mayoría parlamentaria, ese era el Duque de Wellington y a él acude Castlereagh, solicitándole que redacte un Memorandum sobre la situación en España.

Arthur Wellesley tras una notabilísima carrera militar en las colonias y en el continente europeo, había sido reconducido por su gobierno hacia las labores diplomáticas. Se intentaba, por un lado, aprovechar el prestigio que el ya duque había adquirido en todas las cortes continentales y, por otro, alejar de las clases populares al hombre más famoso de la Inglaterra del momento. Ya en los primeros tiempos tras el fin de la guerra peninsular y aprovechando sus contactos con España, el gobierno "tory" utilizó, sin éxito, al duque como portavoz del malestar que en Gran Bretaña ocasionaban las inclinaciones absolutistas de Fernando VII. Ahora se requería su autorizada opinión sobre "los asuntos de España".

Redactado el 16 de abril, este informe de Wellington ${ }^{10}$ comulga en to fundamental con las opiniones que desde amplios sectores de la oposición parlamentaria se venían expresando y que habian empezado a hacer mella en los prohombres del partido en el poder. Desaparecida la amenaza napoleónica, Gran Bretaña debía volver a su comportamiento tradicional, evitando desperdiciar energías en el continente y concentrán-

${ }^{8}$ PRO: FO 185/80. Madrid, 13 de marzo de 1820. De Henry Wellesley a Castlereagh.

- Sobre la postura rusa durante el trienio: SCHOP, A. M. Un siglo de relaciones diplomáticas y comerciales entre España y Rusia. 1733-1833. Madrid 1984, págs. 263 a 335.

${ }_{10}$ P.R.O.: F.O. 185/79, 16 de abril de 1820 . Memorandum del duque de Wellington sobre los asuntos españoles. 
dose en su poder marítimo. Buscando, por tanto, razonar los motivos para una «no-intervención», Wellington parte de una consideración previa fundamental: Fernando VII ha aceptado la Constitución y no hay constancia de que haya solicitado asistencia de ningún poder europeo contra sus tropas rebeldes. El hecho de que haya sido forzado a alterar su sistema de gobierno por la actitud de parte de sus tropas no le parece elemento a valorar. Al igual que a su hermano el embajador, le parece más digna de tener en cuenta la actitud del pueblo español, que "así como antes de 1814 se sentian poco ligados a la "Constitución", ahora no se sienten vinculados al rey y a su autoridad", manteniéndose salvo pequeñas excepciones ajenos a lo que ocurre a su alrededor. ¿Cómo podrían las potencias europeas justificar una intervención sin haber sido llamados?.

Pero, al margen de la inexistencia de razones que legitimasen una intervención, Wellington recurre a sus experiencias como militar en la península y a su supuesto conocimiento del carácter español para defender la inconveniencia de cualquier actuación extranjera en España. A su juicio, ninguna nación ha debido nunca tanto a otra como España a Gran Bretaña. Se les proporcionaron armas, dinero, suministros y todo lo necesario para llevar adelante su guerra por la independencia; se luchó con ellos; se reconquistaron ciudades que luego les fueron entregadas, en resumen "se hizo todo lo necesario para asegurarse la buena voluntad y la confianza de las gentes de España". Sin embargo, y pese a todo ello, el orgullo y la desconfianza hacia el extranjero intrínseca al carácter español les llevó a despreciar los consejos británicos a la hora de redactar su constitución, tomando como modelo - aunque sin confesarlo- los textos de la Asamblea Nacional francesa, uporque no querían que les creyesen influidos por esa nación extranjera con la que habian tenido que contar para su defensa, para que les proporcionase los medios necesarios para salvarse del enemigo y asegurarse su futura independencia". Si ésta es la reacción española ante una interferencia extranjera amistosa, los aliados no deben olvidar que sería mucho más virulenta ante una intromisión hostil. Sobre todo, opina Wellington, si viniese de parte de los franceses, los extranjeros más odiados en la península. La creciente tendencia aislacionista en asuntos continentales; el desprecio hacia unos españoles, desagradecidos y atrasados, y que en última instancia sólo constituyen un peligro para si mismos, y el temor a cualquier aumento de la influencia francesa en Europa, están tras este informe de Wellington.

El análisis que Castlereagh realiza de la situación, aun repondiendo a las mismas preocupaciones, es más global y en él se utilizan argumentos fundamentalmente políticos y diplomáticos. Sus ideas sobre el tema 
español y su vinculación con las relaciones británicas con las demás potencias aliadas son suficientemente conocidas ${ }^{11}$ y quedaron perfectamente expresadas en su memorandum de mayo. Haciendo suyas las ideas desarrolladas por Wellington en el informe antes citado, señala la escasa prudencia de una intervención en España, aun en el caso de que ésta estuviese justificada. Reconoce que la situación europea es delica$\mathrm{da}$, al existir varios estados que están reorganizando sus gobiernos de acuerdo con un sistema representativo. Pero, aunque España ha dado un mal ejemplo "con un ejército sublevado y un monarca que ha jurado una constitución que difícilmente contiene en su marco la apariencia de una monarquía", tiene muy claro que Europa no va a verse envuelta en ningún peligro a causa de los ejércitos españoles ${ }^{12}$. Por otra parte, la alianza no deberia equivocar su finalidad y extralimitarse más allá de las funciones para las que fue creada. Castlereagh no deja de señalar las especiales caracteristicas del sistema político vigente en las islas británicas. Mientras el emperador de Rusia, máximo defensor de la posibilidad de adoptar medidas contra los liberales españoles, no debe responder ante nadie de sus decisiones, el monarca británico debe contar con su Parlamento y con una opinión pública que se había manifestado muy contraria a la política absolutista de Fernando VII. En la especial situación del país, "cuando se requiere toda la energía del estado para unir a los hombres razonables en defensa de nuestras instituciones existentes y para derrotar el espíritu de traición y deslealtad que, en algunos distritos manufactureros en particular, prevalece entre los órdenes inferiores, es del mayor interés que el sentimiento público no se distraiga por ninguna innecesaria intervención del gobierno en acontecimientos exteriores, que no se tiene ningún medio o muy imperfectos de contrarrestar" ${ }^{13}$. Solamente una amenaza directa contra el rey, que duda se llegue a producir, o una política agresiva contra Portugal, a quien están obligados por un tratado, debería, a juicio de Castlereagh, apartar al gobierno británico de una línea de conducta no intervencionista.

Además de este memorandum que se discutió en el Gabinete y fue presentado luego ante el rey, tenemos un buen resumen de sus aspectos

\footnotetext{
pañoles.

${ }^{13}$ Los últimos años en Gran Bretaña habian sido ricos en desórdenes provocados por el descontento social. En enero de 1820 había muerto Jorge III y en febrero tuvo lugar la conspiración de Cato Street, en la que se habia proyectado asesinar al Gabinete. En primavera estallaria "el asunto de la reina" que supuso la más grave crisis política a la que tuvo que enfrentarse Liverpool.
}

11 Ver WeBster, CH. K. The Foreign Policy of Castlereagh. 1815-1822. London 1925.

${ }^{12}$ P.R.O.: F.O. 185/79, mayo 1820. Memorandum de Castlereagh sobre asuntos es- 
más prácticos en las instrucciones secretas que envió a su embajador ante la Corte española el 25 de abril ${ }^{14}$. Aunque el rey y el gobierno de Gran Bretaña deseaban un cambio en el sistema introducido por Fernando VII, no pueden menos que lamentar las circunstancias bajo las cuales se ha producido, así como el resultado final a que se ha llegado: la puesta en vigor de la Constitución de 1812. Para los "tories", e incluso para algunos de los miembros más moderados de la oposición, este texto tenía graves defectos - fundamentalmente «no asegurar la participación del principio monárquico con suficiente fuerza y dignidad" y no reconocer la existencia de dos Cámaras-y de no sufrir profundas modificaciones no permitiría a España dotarse de «un sistema de gobierno moderado y bien regulado, libre en sus principios, pero exento de las semillas de turbulencia y agitación que parecen estar profundamente sembradas en la estructura de la constitución en cuestión». Henry Wellesley debe «en todo momento, sin ninguna vacilación y con la debida delicadeza" expresar esta opinión al gobierno español. Pero debe evitar cualquier apariencia de interferencia en sus asuntos internos.

La situación diplomática de Gran Bretaña era delicada y había que intentar escapar de posibles malas interpretaciones de su actuación. Castlereagh no olvidaba que, ya en febrero, el duque de San Fernando había presentado una queja ante la embajada británica por la ayuda que supuestamente se prestaba desde Gibraltar a los insurgentes, a cambio de facilidades para introducir géneros de contrabando en los puertos por éstos controlados. Al mismo tiempo, los liberales españoles esperaban recelosos la toma de posición británica, dolidos por lo que, a su juicio, habia sido una actitud demasiado condescendiente hacia el gobierno absolutista de Fernando VII. Por su parte, los franceses habian hecho circular entre el cuerpo diplomático en París el rumor de que Gran Bretaña estaba detrás de la revolución española ${ }^{15}$. A la espera de nuevos acontecimientos en la Península y confiando en tener pronto interlocutores moderados con los que poder dialogar, Castlereagh buscaba mantener una posición equidistante entre absolutistas e insurgentes, así como marcar distancias frente a los socios más reaccionarios de la coalición.

Mientras se iniciaba una intensa actividad diplomática en las cancillerías británicas ante las potencias europeas, Wellesley se centró, durante el resto del año 1820, en continuar negociando con las autoridades peninsulares aquellos temas pendientes que venían formando parte de la

${ }_{14}$ P.R.O.: F.O. 72/233, 25 de abril de 1820. De Castlereagh a Henry Wellesley.

15 Ibidem. 
agenda hispano-británica, fundamentalmente la posibilidad de un nuevo tratado de comercio, el cumplimiento de los acuerdos sobre la trata de esclavos y las reclamaciones británicas por deudas contraídas por España durante la guerra de la independencia. Pero los tiempos no eran propicios a este tipo de conversaciones. El cese del duque de San Fernando, predispuesto según Wellesley a concluir un acuerdo comercial, frenó cualquier discusión sobre el tema. En cuanto a la trata de esclavos negros, el tratado de 23 de septiembre de 1817 estipulaba que la participación española en este tráfico cesaría el 30 de mayo de 1820 -más unos meses de prórroga para completar viajes iniciados antes de esa fecha-, plazo que los españoles intentan por todos los medios ampliar. A las peticiones de flexibilidad españolas se contraponen las protestas británicas por el aumento del tráfico en los momentos inmediatamente anteriores a la finalización del plazo y por la falsificación de fechas en abundante documentación. Las comisiones mixtas creadas a partir del tratado en La Habana y Sierra Leona, para estudiar posibles desacuerdos en su aplicación y cumplimiento, estaban teniendo muchos problemas de funcionamiento y parte del trabajo recayó directamente sobre Wellesley ${ }^{16}$.

Otro tema económico que requirió su atención fue la negociación del reconocimiento de una deuda de España con Inglaterra, por los suministros y dinero enviados desde la isla a la península durante la guerra de la independencia. Ya en noviembre de 1814, recibió Wellesley una comunicación del Foreign Office pidiéndole que informase al Gobierno español de las intenciones del británico de preparar una estimación del valor de sus aportaciones a España y que solicitase a los funcionarios españoles que hiciesen otro tanto. Sin embargo, amparándose en la mala situación del departamento de finanzas español y para evitar la mala influencia que suscitar este tema podia tener en las negociaciones en curso por aquellas fechas - tratado de abolición de la trata-, Wellesley aconsejó a su Gobierno posponer el contencioso. Sorprendentemente, el año 1820 parece al representante británico un momento más adecuado para iniciar este debate. A la altura del mes de septiembre, los favorables acuerdos de las Cortes españolas sobre un empréstito holandés anterior a la guerra, animaron al embajador británico a presentar sus demandas confiando en obtener el reconocimiento de al menos parte de la deuda, algunas ventajas comerciales y, quizás, una repercusión en un terreno

${ }^{16}$ State Papers (SP). Vol. 8, 1820-21, mayo-julio, 1820. Correspondencia entre Wellesley, Jabat y Pérez de Castro. 
muy diferente, recordar a los parlamentarios españoles que un elemento fundamental en su lucha contra Napoleón fue el apoyo británico ${ }^{17}$.

Junto a esta actividad de índole principalmente económica, Henry Wellesley se preocupaba de enviar a su gobierno información de índole política que pudiera ser útil a Castlereagh en sus negociaciones tanto con su Parlamento, como con las potencias aliadas. La situación del país no era desde su punto de vista muy alentadora. En sus informes presenta a un monarca incapaz de inspirar confianza a ninguno de los grupos y se hace eco de la existencia de algunos "complots" tendentes a sustituir a Fernando por el infante don Francisco, "que ha mostrado su simpatía por el nuevo orden de cosas" ${ }^{18}$. Presenta a los políticos liberales divididos en dos grupos, aquellos cuyos principios son más moderados, normalmente gente que ha pasado los últimos años en el extranjero y "ha podido corregir sus ideas de libertad examinando las instituciones de otros paises, especialmente de Gran Bretaña", y los que han vivido en el país y han sido testigos de la violencia y la injusticia del sistema anterior. Estos últimos, a los que denomina “jacobinos", serían los más opuestos al rey y los que desean «imponer todo tipo de restricciones a la autoridad real» ${ }^{19}$. Si bien en las Cortes hay mayoría de moderados, que han reconocido a Wellesley en conversaciones privadas su creencia en la necesidad de introducir algunos cambios en la Constitución de 1812 , les ha encontrado reacios a la creación de una segunda Cámara. «El espiritu fanático de los órdenes superiores y la falta de educación y extrema ignorancia de la primera clase de la nobleza» impedirian, según sus interlocutores, los beneficios que podrían esperarse de este órgano ${ }^{20}$.

Un tema al que los británicos eran especialmente sensibles era el portugués, su aliado desde hacia más de un siglo. El gabinete Liverpool temía un aumento de la influencia española sobre su vecino, que pudiera repercutir negativamente en su “relación especial". Las noticias que Wellesley hacía llegar a sus jefes no contribuian a tranquilizarlos. En España se hablaba de la posibilidad de que Portugal siguiera su ejemplo y era evidente que se empleaba al embajador español en Lisboa, Pando, para acelerar este proceso ${ }^{21}$. A sus protestas, el nuevo secretario de estado, lereagh.

17 PRO: FO. 72/236. Madrid, 11 de septiembre de 1820. De Henry Wellesley a Cast-

is Ibidem. Madrid, 24 de julio de 1820. De Henry Wellesley a Castlereagh.

19 Ibidem.

20 PRO: FO 185/80. Madrid, 27 de mayo de 1820. De Henry Wellesley a Castlereagh.

${ }^{21}$ Sobre este tema ver EIRAS RoEL, A., "Política hispano-portuguesa en el trienio constitucional", en Hispania. Tomo XXIII, 1963, págs. 401-454. 
Pérez de Castro, respondia reiteradamente que los representantes españoles en el extranjero tenían orden de no intervenir en asuntos internos portugueses. Los acontecimientos de agosto en Portugal corroboraron los peores temores de Wellesley. Sin embargo, para tranquilidad británica los dos regímenes nunca llegaron a un entendimiento.

Ya en los primeros meses de vida del nuevo poder liberal español, los británicos mostraron estar muy interesados en las relaciones de las nuevas Cortes y gobierno con las colonias en América. Si la distinta valoración de la revolución española y sus repercusiones provocaba fricciones entre Gran Bretaña y algunas de las potencias continentales, entre ellas Francia y Rusia, estos dos países, junto a los Estados Unidos, eran los principales competidores de los británicos a la hora de obtener ventajas de los problemas que enfrentaban a las colonias y la metrópoli. Desde comienzos de siglo y, sobre todo, a partir de la guerra de la independencia, las colonias españolas habian aumentado sus lazos comerciales con Gran Bretaña, convirtiéndose en uno de los principales mercados para los productos de las islas. Castlereagh debía intentar por todos los medios diplomáticos a su alcance que una intervención extranjera en América pudiese alterar esta favorable situación.

Una vez terminada la guerra peninsular, España había hecho gestiones cerca de algunos gobiernos europeos ofreciendo ventajas económicas a cambio de ayuda para recuperar el control total sobre sus colonias. La postura británica en los primeros años de reinado de Fernando VII, defendida en Madrid por Wellesley y, en su ausencia, por Vaughan, era favorable a que las colonias quedasen bajo soberanía española, pero recomendaban la introducción de algunos cambios en el sistema colonial español, tanto en lo referente a los derechos políticos de los americanos, como - y sobre todo - en la organización económica. Aun aceptando que España podía conservar una relación preferencial, solicitaban se proclamase la libertad de comercio. Confiados en su superioridad, se oponían a la concesión de privilegios comerciales sólo a algunos países, aunque Gran Bretaña fuese uno de ellos. Si España se comprometía a dar algunos pasos en este sentido o al menos alguna prueba de su buena voluntad, el gobierno británico resistiria las presiones que estaba recibiendo para reconocer a algunas de estas colonias revoltosas y, algo muy importante para los españoles, intentaria evitar que los Estados Unidos lo hicieran ${ }^{22}$.

${ }^{22} \mathrm{El}$ mejor resumen de la postura británica hacia las colonias españolas en América en estas fechas sigue siendo: WEBSTER, $\mathrm{CH}$. K., "Castlereagh and the Spanish colonies. I. 1815-1818", en English Historical Review. XXVII, 1912, págs. 78-95 y "Castlereagh and the Spanish colonies. II. 1818-1822", en English Historical Review. 1915, XXX, págs. 631-645. 
Aunque ya en febrero de 1820 Wellington señalaba que "ahora deben considerar sus colonias como totalmente perdidas» ${ }^{23}$, muchos británicos creyeron durante un corto tiempo que los liberales podrían tener mejores relaciones con sus colonias que los absolutistas. En octubre, Wellesley informaba a Castlereagh del rumor de que las Cortes estaban dispuestas a abrir totalmente el comercio con América a los extranjeros, aunque contra el pago de elevados impuestos que proporcionasen una cierta ventaja al comercio procedente de España ${ }^{24}$. Pero hubo pocas variaciones en la política española hacia América y pronto los británicos se darian cuenta de que Wellington había acertado. España no era el interlocutor adecuado en temas coloniales en América.

\section{LAS RELACIONES HISPANO-BRITÁNICAS DURANTE $1821 Y 1822$}

Los años 1821 y 22 fueron relativamente tranquilos para los representantes británicos en España, el tema español se debatía fuera de las fronteras, en esferas superiores lejanas a sus competencias, y su misión quedaba limitada al seguimiento de los temas ya antes esbozados y a intentar calmar los recelos españoles ante la postura que los británicos podian adoptar respecto a la revolución española. En sus entrevistas con Pérez de Castro, el secretario de Estado español, Wellesley alternaba las reclamaciones y protestas formales con mensajes de calma y solicitudes de moderación.

A las peticiones españolas para que se ampliase el plazo dentro del cual aún se consideraría lícito el tráfico de esclavos, Gran Bretaña respondía de forma intransigente, recordando los compromisos adquiridos por los españoles en el tratado de 1817. Las instrucciones de Castlereagh a su embajador sobre este tema no dejaban lugar a dudas ${ }^{25}$. Mientras las Cortes españolas discutían la postura a adoptar hacia la trata, los abusos continuaban y el Secretario de Estado británico se enfrentaba en su Parlamento a numerosas denuncias y protestas por el incumplimiento español del tratado. Wellesley debía referirse siempre al

\footnotetext{
${ }^{23}$ Wellington Dispatches. 2nd Series. i. 98, 12 de febrero de 1820. De Wellington a Beresford.

24 PRO: FO 72/237, 19 de octubre de 1820. De Wellesley a Castlereagh.

${ }^{25}$ S.P. 1821-1822. Vol. 9, 16 de febrero de 1821. De Castlereagh a Wellesley.
} 
acuerdo firmado en 1817, insistiendo en que después del 30 de mayo de 1820 no era legal "comprar o transportar esclavos", aunque se había dado un plazo de cinco meses para completar viajes iniciados con anterioridad a dicha fecha. El representante británico debia insistir en un cumplimiento a rajatabla de lo firmado y además recordar a los españoles que seguian existiendo reclamaciones insatisfechas por capturas y daños a propiedades británicas en las colonias españolas en América desde 1804.

El unánime apoyo de las Cortes españolas a la solicitud del conde de Toreno para que se nombrase un comité que estudiase el asunto de la trata y las manifestaciones que algunos prohombres liberales hacian ante Wellesley señalando su oposición a "tan inhumano tráfico», animaron a éste a enviar a Catlereagh informes en los que preveía una pronta solución del problema ${ }^{26}$. Sin embargo, una de las últimas comunicaciones de Henry Wellesley a su gobierno, antes de dejar su puesto en España a mediados de abril, expresaba su profunda decepción ante el rechazo por parte de las Cortes españolas a cualquier medida tendente a limitar la trata de esclavos ${ }^{27}$. Los problemas continuarían en el futuro. En realidad, la esperanza de que los liberales adoptasen una política más abierta que los absolutistas en este tema, sólo mostraba la incomprensión británica, que no tenía en cuenta los problemas que cualquier disposición en este sentido acarrearía al gobierno español, al provocar una reacción sin duda virulenta en las colonias, especialmente en algunas que aún se mantenían fieles a la metrópoli.

Pero a la dureza de la política británica hacia España en temas comerciales y económicos, se unía una actitud mucho más contemporizadora en asuntos políticos. En las conversaciones entre Wellesley y Pérez de Castro abundan las palabras tranquilizadoras por parte británica, asegurando que "no hay intención de atacar la Constitución española", siempre que no haya pruebas claras de intenciones expansionistas por parte de los liberales ${ }^{28}$. La postura de las potencias continentales respecto al tema de Nápoles preocupaba hondamente al gobierno liberal en estas fechas y, a lo largo de sus entrevistas con el ministro español, el embajador británico pudo observar una especial animadversión hacia Francia, que de los cinco poderes aliados es "quien, en este momento goza menos del favor de los españoles» ${ }^{29}$. Pero la postura del represen-

\footnotetext{
${ }^{26}$ Ibidem. Madrid, 26 de marzo de 1821. De Wellesley a Castlereagh.

27 Ibidem. Madrid, 2 de enero de 1821. De Wellesley a Castlereagh.

28 PRO: FO 72/244. Madrid, 2 de enero de 1821. De Wellesley a Castlereagh.

${ }^{29}$ Ibidem. Madrid, 7 de febrero de 1821. De Wellesley a Castlereagh.
} 
tante de Londres tampoco era fácil. Wellesley se queja de la "molesta situación» en que se ha encontrado los últimos meses, debido a los recelos de que hace gala la opinión pública -excitados por los afrancesados, "nuestros eternos enemigos en este país"- ante las intenciones británicas hacia el sur de Europa, especialmente hacia España ${ }^{30}$.

En 1821, se abrió un nuevo frente de negociación para Wellesley, la Corte. A sus intentos por moderar a los liberales se unirían ahora sus esfuerzos por lograr lo propio en las filas absolutistas. El rey salió de su aislamiento y comenzó a entrevistarse con los embajadores extranjeros, entre ellos el británico. A las quejas regias por su seguridad se unian firmes propósitos de aceptar una constitución reformada y promesas de nunca volver al despotismo. En uno de sus cada vez más frecuentes contactos con personas cercanas al monarca, -encuentros rodeados de todas las precauciones posibles, "más por su seguridad que por la propia», según Wellesley ${ }^{31}$ - un tal «M. Gómes" le hizo entrega de un texto escrito de puño y letra por Fernando VII, con el que el rey quería demostrar al embajador británico su favorable disposición a aceptar una Constitución «razonablemente modificada" ${ }^{32}$. Los puntos contenidos en dicho documento, que Wellesley transmitió inmediatamente a Castlereagh, eran los siguientes: “1. ${ }^{\circ}$ Cortes por estados, es decir según la forma en que eran convocadas en el pasado. $2 .^{\circ}$ Soberania del rey. $3 .^{\circ}$ Libre derecho de veto. $4 .^{\circ}$ Imposibilidad de redactar ninguna ley sin previo conocimiento del rey. $5 .^{\circ}$ Abolición de los partidos que se denominan serviles y liberales. $6 .^{\circ}$ Introducción de una fuerza extranjera suficiente para mantener la tranquilidad en el reino hasta el momento de su entera pacificación" ${ }^{33}$. Wellesley no necesitaba más pruebas para comprender que sólo Fernando podía denominar a la aplicación de estas medidas una reforma "moderada" de la Constitución y en su respuesta a Gómez no dejó de manifestarlo. Con gran ironía y algo de cinismo, aconsejó al rey que destruyera el documento y, en el caso de que tomara la decisión de hablar con sus ministros sobre una reforma constitucional, le recomendaba que se limitase a hacer manifestaciones de tipo general, por ejemplo, afirmar que estaba dispuesto a cualquier modificación que los representantes de la nación juzgasen apropiada, pero rogaba al monarca que no descendiese a discutir los detalles. A los ojos de Wellesley aun era posible que los liberales, animados por el ejemplo de Nápoles y Portugal, llevasen a

\footnotetext{
${ }^{30}$ Ibidem. Madrid, 25 de febrero de 1821. De Wellesley a Castlereagh.

${ }^{31}$ Ibidem.

${ }^{32}$ Ibidem.

${ }^{3}$ I Ibidem.
} 
cabo una reforma moderada de la Constitución de 1812, que contemplase la división del legislativo en dos Cámaras y concediese un mayor poder a la Corona. Fernando, con manifestaciones como la anterior y apoyando conspiraciones absolutistas, sólo ocasionaría problemas y movería a los liberales a una mayor intransigencia, que dificultaría la postura británica ante las potencias continentales ${ }^{34}$.

En abril de 1821, Lionel Hervey se hacía cargo de la representación británica en España, casi un año después de que Henry Wellesley hubiese solicitado el relevo. Su menor peso e influencia en el escenario español quedan claramente de manifiesto en su actuación, que también se vio afectada por los problemas que el Gobierno británico tuvo en política interior, tensiones que debilitaron su situación y motivaron algunas vacilaciones en la toma de decisiones. Sus relaciones con Bardaji, quien sustituyó a Pérez de Castro al frente de los asuntos exteriores, quedaron limitadas a las ya habituales recriminaciones por el incumplimiento del plazo fijado en el acuerdo de 1817 sobre la trata — plazo que ahora los españoles quieren ampliar a dos años-, a la presentación de reclamaciones por daños ocasionados a intereses británicos y al intento de llevar adelante unas negociaciones formales sobre el pago de la deuda española por la ayuda recibida durante la guerra de la independencia. Aunque en ningún documento oficial procedente del Foreign Office se hace mención expresa de ello, Hervey parece encargado de aprovechar al máximo los deseos españoles de granjearse la buena voluntad británica de cara a las futuras discusiones del tema español en Europa ${ }^{35}$.

A finales del año 1821 el gobierno Liverpool recuperó el control de la situación en Gran Bretaña, reconciliándose con la opinión pública y el monarca. A ello se unió el acercamiento a Austria en temas internacionales, fruto de la conferencia de Hannover. Castlereagh se encontraba en una mejor situación para hacer frente a la crisis que se avecinaba en España, en la que se verian involucradas todas las potencias y que afectaría a las relaciones con las colonias en América que tanto interesaban a Gran Bretaña. Ya en enero de 1822 se comunicó a Hervey que William À Court sería enviado como embajador a España en breve plazo. À Court, que habia sido representante británico ante la Corte de Nápoles en los difíciles momentos de Troppau y Laibach, parecía más preparado para defender la política de Castlereagh en los difíciles tiempos venideros ${ }^{36}$. Hasta su llegada en septiembre, Hervey siguió defendiendo

\footnotetext{
34 Ibidem. 254.

${ }^{35}$ La poco atractiva gestión de Lionel Hervey se encuentra recogida en PRO: FO 72 /

36 PRO: FO 72/254, 15 de enero de 1822. De Castlereagh a Lionel Hervey.
} 
los intereses británicos y enviando informes cada vez más alarmistas sobre la situación interna española. El país se encontraba en un estado anárquico y no había que descartar una guerra civil ${ }^{37}$. Las conspiraciones absolutistas, contra las que Wellesley había prevenido a Gómez, habian cristalizado en julio con las consecuencias negativas para la moderación previstas por el anterior embajador.

Mientras, Castlereagh preparaba su política de cara al Congreso que los poderes reunidos en Laibach habian previsto para otoño del año 1822. Por sus movimientos a lo largo de estos meses quedó claro que su principal preocupación en el tema español residia en las repercusiones que una intervención extranjera en la península pudiera tener en las colonias españolas en América. En reuniones con Chateaubriand reiteró al representante francés que su gobierno no deseaba ventajas territoriales en Hispanoamérica, sino únicamente libertad de comercio. Por otra parte, aseguró la disposición británica a resistir a las presiones que por parte de algunas colonias se recibían para que el gobierno de Londres las reconociese oficialmente. Aunque estaba a favor de un reconocimiento comercial informal, enviando cónsules que vigilasen los intereses británicos, por el momento no sería político ${ }^{38}$.

\section{CANNING, À COURT Y EL FIN DEL TRIENIO CONSTITUCIONAL}

A las pocas semanas de la llegaba a España de William À Court se producía un cambio importante al frente de la política exterior británica. El suicidio de Castlereagh, marqués de Londonderry desde poco tiempo antes, llevó a Liverpool - preocupado por la escasa representación de peso del gabinete en los Comunes- a designar a Canning como secretario de Estado para el Foreign Office. Cuando llegó a este puesto ya habia pasado por otros cargos importantes, estaba a punto de partir hacia la India como Gobernador General y era bien conocido por sus conciudadanos y entre los políticos extranjeros. Aunque no siempre había compartido los puntos de vista de Castlereagh, su rival en más de una ocasión dentro del partido, cuando llegó el momento de diseñar su política exterior encontramos más cambios en la forma que en el fondo. Canning supo utilizar al Parlamento y a la opinión pública para respaldar $y$, en ocasiones, justificar una postura que difirió en muy poco de la

\footnotetext{
${ }^{37}$ Ibidem. De enero a septiembre de 1822. De Hervey a Castlereagh.

38 Webster, CH. K., The Foreign Policy..., pág. 642-643.
} 
formulada por Castlereagh en mayo de $1820^{39}$. Wellington había sido designado para sustituir al marqués de Londonderry en el congreso de Verona y Canning mantuvo este nombramiento, introduciendo pequeños cambios en las líneas directrices diseñadas por el anterior secretario de Estado. Desde los acontecimientos de julio, España había pasado a ser el centro de atención para Europa. Para los intereses británicos, pasó de un segundo puesto en orden de prioridades, por detrás de Turquia, a primer lugar de cara a la ya inminente conferencia. En ella, Wellington, siguiendo la línea trazada por Castlereagh, deberia defender la "no intervención" en asuntos internos españoles, por no ser una amenaza para los otros países, y marcaria distancias con las potencias continentales, resaltando las diferencias entre un pais auténticamente constitucional como Gran Bretaña y los componentes de la Santa Alianza.

Las noticias de su actuación en Nápoles habian precedido a Sir William À Court en su viaje a Madrid. Wellesley había tenido que defenderle ante el gobierno español, que le acusaba de haber mantenido una postura intransigente ante la revolución napolitana. Su difícil labor a lo largo de los últimos meses de vida del trienio constitucional no facilitó una mejoria en sus relaciones con los liberales españoles. Poco después de presentar sus credenciales, À Court envía su primera estimación de la situación española que, a su juicio, ofrece la ventaja de no verse afectada por prejuicios, dado el poco tiempo que lleva en la península ${ }^{40}$. A la imagen romántica que en Gran Bretaña se tenía de España, fruto en parte de la propaganda favorecida por el gobierno británico en las fechas inmediatamente anteriores a su entrada en la guerra peninsular y del éxito en dicha confrontación, imagen en la que se presentaba a España como ejemplo máximo de lucha por la libertad y de unidad frente a la intervención extranjera, opone À Court la de un pais agotado, dividido, carente de fuerza moral y física, donde la mayoria son incapaces y unos pocos corruptos. La otra España, la de los hombres extraordinarios, "la ideal, sólo existe en la imaginación y no se parece en nada a la realidad". Para su pesar, los moderados han desaparecido, la lucha está centrada entre los dos extremos, absolutistas y los más revolucionarios, y sólo se observa un resto de entusiasmo y fortaleza en los periódicos y en los escritos y discursos de algunos de los miembros más violentos del "partido revolucionario". En lo único en que ha podido observar una cierta unanimidad ha sido en el miedo a la vuelta atrás, pero, a su juicio,

39 Para un planteamiento general ver Temperley, H., The Foreign Policy of Canning, 1822-1827. London 1966, (1. ${ }^{a}$ ed. 1925).

40 PRO: FO 72/259. Madrid, 7 de octubre de 1822. De William À Court a Canning. 
se trata más de «miedo al despotismo en manos de este rey, que al despotismo en sí mismo". El balance final en éste, uno de sus primeros informes a Canning, es desolador: "No es ésta o aquella forma de gobierno la que hará que España vuelva a ser lo que fue. Aun con el más perfecto sistema que la sabiduría humana haya inventado o invente jamás, pasarán generaciones antes de que pueda volver a ocupar su lugar entre las naciones. Las fuentes de su prosperidad y grandeza se han secado y algunas para siempre; su comercio está arruinado; su agricultura abandonada; sus colonias perdidas; su gente desmoralizada y sus energías perdidas. No es más que una gran ruina".

Esta valoración no hacia más que confirmar la opinión de Catlereagh, que Canning había hecho suya. España no podía en ningún caso ser un peligro o una amenaza para los intereses británicos; la actividad británica debía orientarse en otra dirección. La preocupación prioritaria debían ser las colonias españolas en América. Se intentaría impedir una intervención extranjera en España, pero fundamentalmente para evitar que otra potencia pudiera obtener en las colonias influencia y ventajas a las que Gran Bretaña no lograra acceder. En noviembre de 1822 Canning escribía a Wellington, que negociaba con las potencias aliadas en Verona: "Cada día estoy más convencido de que en la actual situación del mundo, de la península y de nuestro país, las cuestiones americanas son con gran diferencia más importantes para nosotros que las europeas y si no aprovechamos la ocasión y las transformamos en nuestro beneficio, lamentaremos la pérdida de una oportunidad que nunca, nunca volverá» ${ }^{41}$.

Durante sus primeros meses de estancia en la península, mientras Wellington defendía la postura británica en Verona, À Court dio cuenta a su gobierno de la buena disposición, al menos de palabra, que estaba encontrando entre los ministros españoles. Conocedores de las "debilidades" de Gran Bretaña, llegaron a ofrecer la negociación de un tratado de comercio, aunque À Court no se veía capaz de precisar si lo hacian "por auténtico convencimiento o por asegurarse el apoyo británico en las presentes circunstancias" ${ }^{42}$. En cualquier caso, y lo mismo que su predecesor, intentaria extraer el máximo provecho de la difícil situación en que se encontraba el gobierno español. La posibilidad de acuerdo comercial, las consabidas reclamaciones de indemnizaciones y por incumplimiento del acuerdo sobre la trata, jalonan este período, en el que Gran

${ }^{41}$ Cit. en Temperley, H., The Foreign Policy..., pág. 103.

42 PRO: FO 72/259. N. ${ }^{\circ}$. De William À Count al secretario de Estado. 
Bretaña intentó introducir, sin demasiado éxito, un nuevo tema: su oferta de mediación entre España y sus colonias en América.

Fue San Miguel, el interlocutor de À Court en su calidad de Ministro de Estado, quien sacó a relucir el tema del tratado de comercio en una de sus primeras conversaciones con el británico. Sus argumentos, de liberal opuesto a sistemas restrictivos también en asuntos económicos, agradaron al representante de Londres. Sin embargo, William À Court no consiguió más que manifestaciones de índole general a favor de la libertad y de la cooperación con Gran Bretaña. San Miguel se negó a facilitarle información sobre cuales serían los puntos a considerar y no quiso entregarle ningún borrador de proyecto que pudiera servir para iniciar unas negociaciones ${ }^{43}$. Pese a esta resistencia del gobierno a suministrar detalles concretos, sus contactos con otras fuentes le permitian aventurar que los españoles estarian dispuestos a reducir de forma considerable los impuestos sobre productos británicos, si por parte de Londres había una disminución de los aranceles que gravaban los vinos y la lana procedentes de la peninsula, y se tomaban medidas para luchar contra el contrabando desde Gibraltar. A estos temas habría que añadir, según $\grave{A}$ Court, el de la seguridad de los súbditos británicos residentes en España y sus propiedades ${ }^{44}$. Pero estas prometedoras conversaciones para Gran Bretaña, mantenidas a lo largo de los meses de octubre y noviembre, entrarian muy pronto en vía muerta ante la resistencia española a abandonar el terreno de las buenas intenciones y por su tendencia a mezclar este tema con consideraciones de tipo político que al embajador británico le parecian fuera de lugar ${ }^{45}$.

El gobierno y las Cortes españoles seguian haciendo públicas manifestaciones de su oposición al tráfico de esclavos, que calificaban de inhumano, pero a Gran Bretaña aún llegaban quejas por el incumplimiento español del tratado de 1817. Por ello, el representante británico tuvo que insistir reiteradamente en Madrid, reclamando que se llamase al orden a las autoridades coloniales responsables de los abusos. Mientras Wellington negociaba en Verona una declaración común contraria a la trata, À Court intentaba conseguir del gobierno español la aprobación de dos artículos, uno declaratorio y otro adicional, para añadir al tratado de 1817 , que garantizasen un mejor cumplimiento de sus fines. Las comisiones mixtas de Sierra Leona y La Habana habian resultado ser inoperan-

\footnotetext{
${ }^{43}$ Ibidem, 10 de noviembre de 1822. De William A Court a Canning.

${ }^{44}$ Ibidem.

${ }_{45}$ Ibidem. Madrid, 16 de noviembre de 1822. De William À Court a Canning.
} 
tes, pues los representantes españoles en África rara vez se encontraban en sus puestos, aquejados de enfermedades reales o imaginarias que achacaban a la insalubridad de la zona, y los comisionados en América alegaban no disponer de instrucciones muy precisas, para así dejar hacer al capitán general y otras autoridades locales. Las rectificaciones de Londres al tratado buscaban poner fin a esta situación obligando a los españoles a tener siempre cubiertas las plazas de comisionados y a adoptar actitudes comunes con los británicos ante las infracciones.

El problema de la trata quedaba solapado, en las negociaciones que mantenia À Court con San Miguel, con el tema de las reclamaciones británicas por daños a sus súbditos y propiedades, pues gran parte de estas quejas se centraban en la actitud de las autoridades cubanas poco deseosas o incapaces de reprimir las actuaciones de los piratas. Aunque en noviembre el embajador británico comunicaba que por primera vez el gobierno español habia reconocido la justicia de sus reclamaciones y era posible algún avance en este tema ${ }^{46}$, el gobierno británico decidió utilizar la fuerza para animar al español a tomar decisiones. El 1 de diciembre Canning -siempre preocupado por evitar malos entendidos con posibles rivales en el escenario colonial- comunicaba a Villèle su intención de enviar un destacamento naval a las Indias occidentales con la misión de atacar a los piratas en sus escondites, para lo cual desembarcaria en Cuba aun sin el consentimiento del gobierno español. Los franceses no debían ver en este comportamiento británico deseos de hacerse con territorios en las colonias españolas, sino sólo una acción en legítima defensa de sus intereses comerciales ${ }^{47}$.

El 10 de diciembre de 1822, San Miguel y À Court firmaban en Madrid las nuevas claúsulas que complementaban el acuerdo de $1817^{48}$. Fue una de las pruebas de la buena disposición española hacia la Gran Bretaña, en estas fechas decisivas para el futuro del gobierno constitucional, y de la capacidad británica para sacar beneficio de las dificultades españolas. El 7 de enero de 1823 Canning podía anunciar que se suspendian las operaciones contra los piratas en territorios vinculados a la Corona española, pues el gobierno de Madrid estaba dispuesto a ofrecer compensaciones a Gran Bretaña. Asi se lo habia comunicado À Court, el 24 de diciembre, informándole de que San Miguel le habia enseñado los papeles que pensaba presentar ante las Cortes, en los que se contem-

\footnotetext{
${ }^{46}$ Ibidem. Madrid, 20 de noviembre de 1822. De William À Court a Canning.

47 Temperley, H., The Foreign Policy..., págs. 105-109.

${ }^{48}$ S.P. Vol. 10. 10 de diciembre de 1822.
} 
plaba «el arreglo de todas nuestras diferencias, incluída 1. una satisfacción por los barcos capturados en las Indias Occidentales (...). 2. el fin del bloqueo proclamado por el gobernador de Portobello. 3 . la revocación de la ley colonial o indiana contra cuyo fortalecimiento hemos protestado enérgicamente. 4. el inmediato pago de nuestras reclamaciones -ya reconocidas por las Cortes- y 5 . autoridad para reglar cualquier otra que demuestre ser justa" ${ }^{49}$. Unos meses después, en un discurso sobre la cuestión española ante los Comunes, Canning afirmaba, no sin cierta ironía, que habia sido una coincidencia "que hubiese sido en las fechas en que se cerraba el congreso de Verona cuando las negociaciones de las reclamaciones británicas habian llegado a una conclusión favorable" ${ }^{50}$.

Pero las tensiones irian creciendo entre Madrid y Londres. A fines del año 1822 À Court se lamentaba de que la complicada situación internacional para España fruto del congreso de Verona y, de forma muy especial, la actuación de Wellington estaban complicando su gestión. El gobierno constitucional había esperado una actitud más decidida de parte británica, en palabras de San Miguel que «hubiesen declarado su inmediata disposición a lanzar el guante contra cualquier poder que interfiriese en asuntos españoles" ${ }^{51}$, y su postura de estricta neutralidad, mientras ellos hacian concesiones ante la dura presión de À Court, les había decepcionado. Probablemente éste fue el motivo de que el gobierno de Londres decidiese enviar a Madrid un representante especial, no para sustituir a À Court, sino para reforzar la presencia británica y cubrir más frentes.

En enero de 1823 llegaba a la península Lord Fitzroy Somerset. Amigo personal del duque de Wellington, había colaborado con él en la guerra de la independencia, fue su asistente en las deliberaciones de Verona y tenía buenas relaciones con España. En teoría, acudia a Madrid en nombre del duque, quien, en su calidad de grande de España, se tomaba la libertad de presionar a sus amigos en aras de una mayor moderación. Canning, al igual que Castlereagh antes que él, estaba convencido de que Wellington era la única persona con prestigio suficiente como para influir en los asuntos españoles y, a través de Somerset, intentaba jugar sus últimas bazas para impedir una intervención francesa

\footnotetext{
${ }^{49}$ P.R.O.: F.O. 72/259. Private. 24 de diciembre de 1822. De William À Court a Canning.

5o Parlamentary Debates. Vol. 8. House of Commons. 14 de abril de 1823. Discurso de Canning sobre las negociaciones relativas al caso español.

${ }^{51}$ P.R.O.: F.O. 72/259. Madrid, 27 de octubre de 1822. De William A Court a Canning.
} 
en la península. Las instrucciones de Wellington a Somerset eran muy claras ${ }^{52}$. Debía entrevistarse con las personas adecuadas y hacerles ver que siendo el rey necesario para el gobierno de su pais, como parte del sistema que ellos mismos habian establecido, era inevitable que concediesen al monarca los poderes y prerrogativas que le permitieran desempeñar sus funciones. En caso contrario, las relaciones familiares entre el monarca español y el francés y el interés que éste tomaba por el bienestar de aquél ocasionarian inevitables tensiones, que bien pudieran desembocar en una guerra. Cualquier español preocupado por la paz y el bienestar de su país debia propiciar una reforma constitucional en esta línea y asi debía hacérselo ver Somerset. Por otra parte, también debia recordaries que su situación económica era desesperada y que nadie en Europa se animaria a prestar dinero a España en las presentes circunstancias. Todo tacto sería poco en su delicada misión y no debía olvidar insistir ante sus amigos en que Gran Bretaña seguia decidida a no intervenir en los asuntos internos de España. Su visita era de carácter privado y sus consejos amistosos. La representación oficial la seguia ostentando À Court.

Somerset inició su labor inmediatamente y pronto comenzó a enviar decepcionantes informes sobre sus resultados. Aunque sus contactos reconocian de forma casi unánime los defectos de la Constitución de 1812, eran conscientes del peligro que el país corría y agradecian el interés del duque de Wellington, no dudaban en afirmar que era demasiado tarde para tomar medidas. Después de los acuerdos de Verona nadie en el pais se atreveria siquiera a mencionar la posibilidad de la más leve reforma constitucional ${ }^{53}$. Así se lo habia comunicado también San Miguel a William À Court, en una entrevista en la que se dio por enterado de la llegada de Somerset y afirmó haber sido informado por el general Álava del carácter de la misión que le había llevado a España ${ }^{54}$. La retirada de los embajadores por parte de las potencias continentales y el discurso del rey Luis XVIII en la apertura del parlamento francés, pocos dias después de la llegada de Somerset, exarcebaron aún más los ánimos y radicalizaron las posturas, condenando al fracaso su misión. Cuando la Corte se trasladó a Sevilla él se quedó en Madrid como cónsul general.

William À Court, por su parte, se encargó durante los primeros meses de 1823 de gestionar los asuntos pendientes, principalmente la apro-

52 S.P. 1822-23. Vol. 10. Londres, 6 de enero de 1823. Memorandum del duque de Wellington a Somerset.

53 Ibidem. Madrid, 25 de enero de 1823. De Somerset a Canning.

54 P.R.O.: F.O. 72/269. Madrid, 24 de enero de 1823. De William À Court a Canning. 
bación en las Cortes de la cantidad que saldaría las deudas reclamadas como indemnización por los británicos, y de buscar una posibilidad de mediación. Viendo cada vez más inevitable un enfrentamiento, el gobierno de Londres buscaba tener un papel en los futuros acontecimientos y comenzó a ofrecer, reiteradamente y a las dos partes en conflicto, su "desinteresada" mediación, sin olvidar en ningún momento la vertiente americana del problema. Ya en enero recibió la primera solicitud de sus «buenos oficios" por parte española, pero en unos términos a su juicio demasiado vagos. Aunque ofrecía la posibilidad de introducir algunas modificaciones en la Constitución y mostraba un cierto respeto hacia la familia real, se negaba a que se hiciese mención de ninguno de estos dos temas en conversaciones con Francia ${ }^{55}$. La esperanza de poder frenar el conflicto gracias a la mediación británica se presentaba remotísima a juicio de À Court, sobre todo por la ausencia en el lado español de una autoridad con la que poder negociar. Aunque individualmente todos reconocían que el peligro era inminente y que la única solución era «seguir las amistosas sugerencias de Gran Bretaña", "colectivamente asumen un falso tono de seguridad y desafío, rechazando cualquier modificación y mediación con celosa persistencia" ${ }^{56}$. La retirada de embajadores y las palabras de Luis XVIII también influyeron negativamente en sus gestiones.

Los principios defendidos en el discurso del monarca francés, criticando la constitución española por no emanar de la Corona, permitieron a Canning una durísima intervención en los Comunes, en defensa de las libertades, la constitución británica y la gloriosa revolución de 1688, que le granjeó el apoyo de la opinión pública e, incluso, de los miembros más radicales de la oposición ${ }^{57}$. Durante unas semanas y utilizando como argumento la actitud favorable a España de su opinión pública, Canning agitó ante Francia el fantasma de una posible intervención británica. El 21 de febrero el gobierno de Londres levantó el embargo que había sobre la exportación de armas a España y sus colonias ${ }^{58}$. Pero, a finales de marzo, en cuanto consiguió seguridades francesas de que no establecerían una ocupación militar permanente en España, respetarian los dominios de Portugal y no se apropiarian de territorios en las colonias espa-

55 P.R.O.: F.O. 72/269. Madrid, 12 de enero de 1823. De William A Court a Canning

${ }^{56}$ Ibidem. Madrid, 15 de enero de 1823. De William À Court a Canning.

57 Parlamentary Debates. Vol. 8. House of Commons. 14 de abril de 1823. Discurso de Canning sobre las negociaciones relativas al caso español.

${ }^{58}$ En el tratado hispano-británico de 1814 Gran Bretaña se comprometió a prohibir la venta de armas a las colonias españolas sublevadas en América. En 1818 y en aras de la neutralidad que el gobierno de Londres defendía, se extendió el embargo a España. 
ñolas en América, hizo llegar al gobierno francés su intención de permanecer neutral.

Mientra Canning demostraba sus dotes políticas y parlamentarias, $\grave{A}$ Court enviaba informes cada vez más alarmistas, ante el cariz que estaba tomando la situación interna en la península. A comienzos de febrero, reclamaba instrucciones para el caso de que el rey fuese obligado a dejar la capital. El día 20 del mismo mes, tenía lugar una entrevista nocturna y rodeada de secreto entre el rey y el embajador británico, que llevó a Somerset como testigo. Teniendo en cuenta los acontecimientos, À Court esperaba encontrar al rey asustado y deseoso del apoyo británico. Sin embargo, y ante su asombro, el monarca - quien les recibió "en la cama, con barba de varios días y en un batín no muy limpio"- se mostró enérgico e intransigente, quejándose de haber sufrido abusos intolerables que eran «la consecuencia natural de la Constitución, que sólo podia calificar como muy mala". Su actitud no habia cambiado desde que hizo llegar aquel papel a Wellesley a través de Gómez. Las posibilidades de que aceptase una constitución reformada le parecieron al embajador británico muy remotas. Si los constitucionalistas se resistian a introducir la más ligera modificación en una constitución que habian sacralizado, el rey y sus seguidores no eran más flexibles. "La violencia de los exaltados, la tozudez de los doctrinaires (sic), la exageración de los serviles y la obstinación de los ministros (...) no dejan camino abierto a ningún tipo de conciliación» ${ }^{59}$. España iba hacia la guerra. Sin embargo, cambios en el gobierno y vacilaciones de todo tipo resucitaron en más de una ocasión el fantasma de la mediación británica.

Fueron unos meses repletos de actividad. Mientra esperaba el desarrollo de los acontecimientos, el representante del gobierno de Londres logró llegar a algunos acuerdos sobre las reclamaciones británicas, siéndoles asignados por las Cortes 40 millones de reales, que, si bien no cubrían todo lo demandado, pudieron ser esgrimidos por Canning ante los Comunes como una prueba del buen hacer de su gobierno ${ }^{60}$. Pero el papel fundamental de À Court consistía en jugar lo mejor posible las escasas cartas que la posición de neutralidad de su gobierno le había dejado, evitando quedar al margen de los futuros acontecimientos.

Frente a la opinión de algunos parlamentarios británicos, que, en sus intervenciones en los Comunes, auguraban una dura lucha por parte es-

${ }^{59}$ Ibidem. Madrid, 20 de febrero de 1823. Confidencial y secreta. De William À Court a Canning.

${ }^{60}$ PRO: FO 72/270. Madrid, febrero de 1823. De William À Court a Canning. 
pañola frente al invasor, la reacción de importantes personajes ante el traslado de la Corte a Sevilla, pidiendo permisos especiales para no tener que seguir al gobierno, llevaba a William À Court a dudar de la capacidad española para oponerse a una intervención extranjera. Frente a la unidad y entusiasmo que mostraron en su lucha contra los franceses en la guerra de la independencia, "ahora es opinión general que la guerra nunca será nacional» y se ponían más esperanzas en la debilidad del ejército invasor y en una intervención británica - en la que todavía creían-que en las virtudes propias ${ }^{61}$. La facilidad con que las tropas de Angulema cruzaron la península le dio la razón.

De Sevilla À Court se trasladó a Gibraltar, negándose a seguir al rey a Cádiz por los, a su juicio, oscuros manejos que rodearon este viaje. Desde la colonia británica siguió ofreciendo sus servicios para lograr una negociación entre Angulema y los constitucionalistas sitiados, convencido de que, para los británicos, era fundamental participar en la toma de decisiones de cara al futuro y de que, para los españoles, sería mejor una negociación, en que obtuviesen algunas garantías para proteger su sistema constitucional, a una derrota completa. Pero todas sus gestiones fueron inútiles.

Canning fue acusado en el Parlamento de haber fracasado en su política, sin embargo, esto no le preocupó demasiado. En octubre lograba una entrevista con Polignac para averiguar las intenciones de Francia sobre las colonias españolas en América, su auténtico caballo de batalla. No hay que olvidar que desde 1814 el comercio de exportación británico hacia las colonias españolas en América había crecido de forma notable y habia que protegerlo ${ }^{62}$. España y los liberales españoles siempre habian ocupado un lugar secundario en sus preocupaciones, convencido de su pequeño papel en el escenario europeo. En cambio, con su política, distante de las decisiones de la Santa Alianza, pero vigilante y siguiendo

${ }^{61}$ Ibidem. Sevilla, 6 de abril de 1823. De William À Court a Canning. Las noticias, en mayo, de la llegada de Robert Wilson y otros voluntarios británicos parecía dar la razón a los españoles que confiaban en la ayuda de Londres. Sin embargo, para À Court sólo era un proyecto sin ningún futuro, en el que los Friends of Liberty malgastarian el poco dinero que habian reunido. Ibidem. Sevilla, 21 de mayo de 1823.

${ }_{62}$ De 1807 a 1814 , las exportaciones habian alcanzado el valor de $£ 444.773$, pasando, de 1822 a 1827 a la sorprendente cifra de £6.244.333. Cit., en TEMPERLEY, H., The Foreign Policy..., pág. 160. Datos desglosados en PRAdos de LA Escosura, L., “El comercio hispanobritánico en los siglos XVIII y XIX", en Revista de Historia Económica. Año II. PrimaveraVerano 1984, núm. 2, págs. 113-162. 
de cerca los pasos de Francia, había obtenido algunos pequeños logros en asuntos pendientes con España y había conseguido frenar un posible avance francés en el escenario americano. Los años siguientes serian decisivos para las ambiciones británicas. 